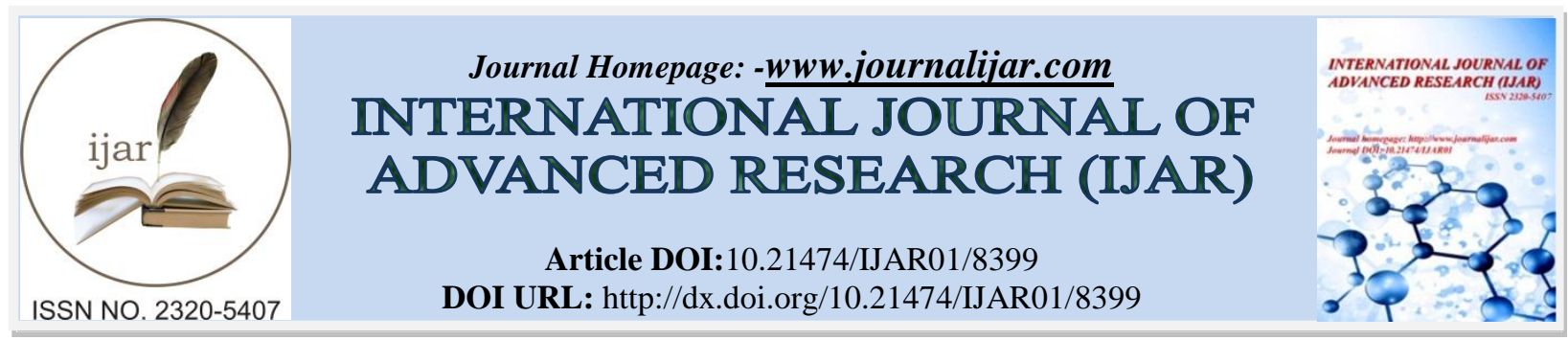

RESEARCH ARTICLE

\title{
THE MEANING, IDEAS, DIMENSIONS AND TYPES OF FREEDOM IN THE HUMAN EXISTENCE.
}

\section{Masna Venkateshwarlu ${ }^{1}$ and Mallesham Sankasala ${ }^{2}$.}

1. Research Scholar in Philosophy at Osmania University, Hyderabad, Telangana State, India.

2. Head of the Department Department of Philosophy Osmania University, Hyderabad, Telangana State (India).

\section{Manuscript Info}

Manuscript History

Received: 12 November 2018

Final Accepted: 14 December 2018

Published: January 2019

\section{Abstract}

\section{Introduction:-}

\section{What is Freedom:}

If you ask one hundred people this question, you'll receive one hundred different answers, because every person understands this phenomenon in his or her own way. I wonder whether this notion can be accurately defined and it seems to me that the answer is no.

Steiner says that we must look for freedom in conscious action. He doesn't say that we will necessarily find it! He explores the various compulsions of motives at different levels, and points out that freedom does not exist if we are still within the grip of the various forces acting within us.

What is freedom? Is it an absolute right? We are born to become free. Freedom is defined from different aspects and according to different cultures, freedom varies from one culture to another. Some define freedom as a natural right, the human being is born with.

Everyone wants to be free and independent from others. Freedom is the right to do what one wants, live where he wants, eat what he wants, learns what he wants, and chooses the religion in which he believes, without ignoring or harming other rights.

The concept of freedom has a long history before it was recognized as a fundamental human right by the international community, and has been entrenched in various legal documents.

How can we live free? From my point of view, we can live free by respecting others rights to live free too. We can't ignore the rights of the people with whom we live in the society. We can't simply do what we want and ignore others. We must take other people rights into consideration.

The idea behind freedom is to be respectful and useful to our society. Freedom is important to everyone. If someone is deprived from this innate right, he will definitely feel as if he is not a respectful human being. When freedom is guaranteed, I can think freely, go where I want, say my opinion without fear from people who would not like my opinion. Freedom of opinion is among the most important branches of freedom.

Corresponding Author:-MasnaVenkateshwarlu.

Address:-Research Scholar in Philosophyat Osmania University, Hyderabad,Telangana State, India. 
The difficulty lies in the human mind; freedom is a great responsibility and the mind wants to be free without becoming responsible. If people are really free, it is doubtful how many would stay with it. The problem with this world is that it is misunderstood down the ages. It has the combinations of burden, duty, seriousness and loss of freedom.

Two Elements are common to most interpretations of 'free'. First, freedom requires an absence of determination or certain sorts of determination, and second, one acts and chooses freely only if these endeavors are, properly speaking, one's own. From here, accounts diverge. Some take freedom (liberty) of indifference or the contingency of alternative courses of action to be critical. Indifference is also constructed as motivational equilibrium, a condition some find essential to the idea that a free choice must be rational.

Historically, there has been an evident proof that freedom is innate to human and that s/he will fight as long as s/he lives to restore his/her innate right to be a free man. The western civilization guaranteed freedom for its own people and occupied poor nations and deprived their people from their rights, including freedom. So, these poor nations fought without rest to restore freedom and autonomy from occupation. Abduction of rights is not a respectful human action. Since God gave us freedom for free, we must do our best to maintain and keep this right.

In the modern society, human rights, self respect have been given much importance which leads to strengthening the concept of freedom. Though 'freedom' was political at first, later it was established morally in the public. Some experts say that 'Freedom' is not necessary to humans because animals which live freely do not possess any kinds of values. But there is a difference between 'human freedom' and 'animal freedom' man is civilized animal and established this own system. Man has an absolute 'soul and divine'. Even Upanishads say 'Soul is God' and 'I am divine'.

\section{Ideas of Freedom:}

Freedom has been mainly concerned at three levels, the first is 'Freedom from', the second is 'Freedom for' and the third is 'Just freedom... neither from nor for'.

'Freedom from' is political, is a reaction, is ordinary and mundane. It is completely past oriented. We fight against the past, we want to get rid of it, we are blessed with it. Man has always tried to be free from things. It is not creative; it is the negative aspect of freedom. Freedom from, at the most, can take always our handcuffs. It is not necessarily beneficial and the whole of history is a proof of it.

The second idea 'Freedom for' is creativity; we have a certain vision that we would like to materialize and we want freedom for it. It is always for the future. It is a spiritual dimension because we are moving into unknown and perhaps, one day into the unknowable. It is future-oriented and more poetic, visionary and utopian. Many people have tried that too, but that too is not possible, because in future-oriented, we can't live in the present. We don't live in the past, we don't live in the future, so we have to live in the present. Visionaries only imagine beautiful utopias they have imagine, but those utopias never become Reality and can't become Reality.

If we react to the past, we are determined by the past. If we forget the past and look at the future, we are still driven by the past but just not aware of it. Looking at the future we dream beautiful dreams but they can't change Reality. The reality remains the same, dreams are very ineffective and impotent.

Hence the first, 'Freedom from' is a reaction; the second, 'Freedom for' is a revolution and the third, 'Just Freedom' is a rebellion - it is present oriented. This is mystic and religious. It is neither from nor for.... No past, no future, just being here now, just living moment to moment with no ideology, with no utopia.

As far as this freedom is concerned, Karl Marx and Sigmund Freud are not opposed to each other; they both agree. Karl Marx says one has to become free from the past, all past social structures, economic structures. His approach is political and Freud's approach is psychological, but both are rooted in the idea of Freedom from. Robert Ovan, an eminent Socialist stated that circumstances change the human attitude and there is no real freedom to Man.

All political reforms are reactions and when we react we are never free. This has to be understood. It only gives you an appearance of freedom, but it is never true freedom. 
Out of reaction 'Total freedom' is not possible, out of reaction "True freedom" is also not possible. Only Total freedom is True freedom. We can go against the past, but just in being against it we are caught by it from the back door.

\section{Dimensions of freedom: \\ Freedom and responsibility:}

Unwilling to abandon practical freedom yet unable to understand how a lack of determination could be either necessary or desirable for responsibility, many philosophers take practical freedom and responsibility to be consistent with determinism, thereby endorsing compatibility.

Freedom is maturity, license is very childish. Freedom is possible only when we are so integrated that we can take the responsibility of being free. The world is not free because people are not mature. Revolutionaries have been doing many things down through the centuries but everything fails. Hence, the more responsible we become, the more free we become, or the more free you become, the more responsibility comes on us. Then we have to be very cautious to what we are doing and what we are saying.

\section{Freedom as a birthright:}

The very idea of giving freedom to others is wrong. Who are we to give freedom to others? It is not something that has to be given. If it has to be given, then there will be the problems that we are facing. So in the first place we are doing something wrong. Giving freedom to others, we have put somebody else first and we have put ourselves second. That is against the ego and it is not going to help in anyway, because we will take revenge for the freedom that we have given. Apart from all these situations, we have to realize that freedom is our birthright and nourishment to our life and lifestyle.

\section{Freedom as the greatest longing of man:}

Freedom is the very essential core of human consciousness. Love is its circumference and freedom is its center. They both are fulfilled together, never separately.

Love without freedom naturally tends to be possessive. The moment possessiveness enters in, we start creating bondage for others and bondage for ourselves. We can't make somebody a slave without becoming a slave ourselves. Whatsoever we do to others is done to us. This is the basic principle to be understood, that love without freedom never brings fulfillment. Love and freedom are not separate things. Either we will have to have both or we will have to drop both. As mentioned before, love is the circumference and freedom is the center. One has to grow in such delicate balance, to where love and freedom can bloom together. It is our potential and our birth right.

\section{Freedom from the past:}

The whole existence has a basic tendency to complete everything. It does not like incomplete things..... they hang, they wait; there is no hurry for existence... They can wait for millions of years. If we have come to terms with the past suddenly, we will be here and now in the present, because then there is no need to move again and again. When we cannot move backwards, only then we move forwards. There is no other way. To move forward is to reach the path. The whole consciousness moving ahead every moment into the unknown. We will become more sensible, vulnerable and open.

\section{Climate of Freedom and Human Existence:}

If parents help their children to be rebellious, the world will be totally revolutionary. And that revolution will not be political. It will be a permanent revolution, because each generation will bring it again onto new altitudes of being and new spheres of consciousness. No spaces will always be opening.

\section{Types of freedom:}

\section{Personal Freedom:}

The Freedom to choose how you will live your life, so long as you are not injuring somebody else when you do so. Under this, I would include things like the right to decide how much salt or trans fat you would like to eat, what drugs to take, etc. Physical Freedom - the possibility for a person to go where s/he wants and do what s/he wants. 


\section{Spiritual freedom:}

The privilege of being able to express one's thoughts or to live according to one's outlook.

\section{National freedom:}

The authority which enables a person to identify and to live with others of his/her people

\section{State freedom:}

The ability of a person to live (preferably in his/her own land) under a Government of his/her choosing.

Political Freedom - This could be either a freedom from government, or the freedom to have a say in who is in charge.

\section{Economic Freedom:}

The freedom to make contracts, to buy and sell, the freedom to work for whom you choose, the freedom to keep you rmoney once you have earned it.

\section{Religious Freedom:}

The freedom to worship (or not) as you choose with your own will and wish, without Government restriction.

\section{Freedom of Movement:}

The right to go where you choose when you choose within your country, without Government interference.

\section{Self Defense:}

The Freedom to defend yourself, your family and your property from theft and violence.

Man only can change the superficial things. it is not a question of changing ideologies and religious aspects but it is a question of living without ideologies, without religious framework and philosophies. When we come out of a prison, we shouldn't step into another. We have to remain in the open sky.

\section{Conclusion:}

Some people consider Freedom to be a synonym of Democracy. Others believe that it is an opportunity to act freely and embody ideas. There are also those who are sure that it is a possibility to do what they want regardless of the impact their actions will have on other people.

I'm definitely sure that everybody knows this statement: "My Freedom ends where the Freedom of another person starts". Within the society, the area of freedom available to each of the individuals is restricted.

A person is freeto do what the laws and social customs should not be forbidden. Still, what distinguishes a free society from other societies is the extent of the restrictions put on freedom. We can hardly say that all the societies are free in the same way.

As for me, I can hardly say that I am a free person, because I observe the rules and traditions of the society. Sometimes I'm not free to act as I want, because I know that it can bring harm to people whom I love and respect. I'm not free to leave the country I live in, because there are too many things, which I cannot leave and too many people, whom I love. But from time to time I feel completely free: for instance, when at dawn I go for a walk in a park and enjoy a new day be born.

\section{References:}

1. 'What is Living and What is Dead in Indian Philosophy' by DebiprasadChattopadhyaya, Chapter10: Problems of Freedom.

2. 'Freedom and Karl Jaspers's Philosophy' by Elisabeth Young-Bruehl

3. 'The Enlightenment: An Interpretation, Vol-II: The Science of Freedom', by Peter GayK. Marx and F. Engels, Werke, 39 vols. (Berlin, 1961-71)

4. 'The Anguished Freedom' by S.MishraPhilosophy and Contemporary Issues' by John R.Burr and Milton Goldinger

5. 'Understanding Philosophy' by James K.Feibleman 'The Greatest Challenge - The Golden Future' by Acharya Rajneesh (OSHO). 